\title{
Follow-up and management of differentiated thyroid carcinoma: a European perspective in clinical practice
}

Martin Schlumberger ${ }^{1}$, Furio Pacini ${ }^{2}$, Wilmar M Wiersinga ${ }^{3}$, Antony Toft ${ }^{4}$, Johannes WA Smit ${ }^{5}$, Franco Sanchez Franco ${ }^{6}$, Peter Lind ${ }^{7}$, Edward Limbert ${ }^{8}$, Barbara Jarzab ${ }^{9}$, François Jamar ${ }^{10}$, Leonidas Duntas ${ }^{11}$, Ohad Cohen ${ }^{12}$ and Gertrud Berg ${ }^{13}$

${ }^{1}$ Institut Gustave Roussy, Villejuif, France, ${ }^{2}$ University of Siena, Siena, Italy, ${ }^{3}$ Academic Medical Center, Amsterdam, The Netherlands, ${ }^{4}$ Royal Infirmary, Edinburgh, United Kingdom, ${ }^{5}$ University Medical Center, Leiden, The Netherlands, ${ }^{6}$ Hospital Carlos III, Madrid, Spain, ${ }^{7}$ Positron Emission Tomography Center, Klagenfurt, Austria, ${ }^{8}$ Portuguese Cancer Institute, Lisbon, Portugal, ${ }^{9}$ Maria Sklodowska-Curie Memorial Institute, Gliwice, Poland, ${ }^{10}$ University of Louvain Medical School, Brussels, Belgium, ${ }^{11}$ Evgenidion Hospital, Athens, Greece, ${ }^{12}$ Chaim Sheba Medical Center, Tel Hashomer, Israel and

${ }^{13}$ Sahlgrenska University Hospital, Gothenburg, Sweden

(Correspondence should be addressed to M J Schlumberger, Service de Médecine Nucléaire, Institut Gustave Roussy, 39, rue Camille-Desmoulins, 94805 Villejuif Cedex, France; Email: schlumbg@igr.fr)

\begin{abstract}
As differentiated (follicular and papillary) thyroid cancer (DTC) may recur years after initial treatment, follow-up of patients with DTC is long term. However, this population has changed, with more individuals being discovered at an earlier stage of disease, so that previous follow-up protocols based mostly on data from high-risk patients no longer apply. We have proposed, in a previous issue of this Journal, an improved protocol for the follow-up of low-risk patients with DTC based on the findings of recent studies. We report here the case of a paradigmatic patient with papillary thyroid carcinoma, with the goal of illustrating the benefits of applying this algorithm in routine clinical practice. We also offer expanded and additional comments on various issues in the management of DTC.
\end{abstract}

European Journal of Endocrinology 151 539-548

\section{Introduction}

We recently reported the recommendations of a group of European experts in the management of differentiated thyroid carcinoma (DTC), and proposed an algorithm (Fig. 1) for the follow-up of low-risk patients with this disease (1). We report here the case of a paradigmatic patient with papillary thyroid carcinoma, with the goal of illustrating the benefits of applying this algorithm in routine clinical practice. We also offer expanded and additional comments on various issues in the management of DTC.

\section{Case report}

A 35-year-old woman was referred to the Thyroid Unit for a $2.5 \mathrm{~cm}$ nodule of the right lobe of the thyroid, which she herself had discovered. She had no local symptoms and was clinically euthyroid. The nodule was firm and regular and there were no palpable lymph nodes in the neck. Her medical history was negative, with no radiation exposure to the neck during childhood and no case of thyroid tumors in her family. Serum TSH was within the normal range, and serum anti-thyroid peroxidase antibodies were negative.
Neck ultrasonography showed that the thyroid nodule was solid and hypoechogenic; there were no other abnormalities in the thyroid gland or in lymph node areas. A fine-needle biopsy indicated papillary thyroid carcinoma. The patient was then informed about the diagnosis and the Thyroid Unit's treatment protocol, with an extensive explanation of potential side-effects and complications. Vocal cord examination was normal. Serum calcium was normal. A total thyroidectomy with a dissection of the central neck compartment was performed. She had no surgical complication.

Histology confirmed that the $2.5 \mathrm{~cm}$ nodule was a non-encapsulated papillary thyroid carcinoma, with two additional tumor foci $(1 \mathrm{~mm}$ each) in the right and two tumor foci ( 2 and $3 \mathrm{~mm}$ ) in the left thyroid lobe. No tumor extended beyond the thyroid capsule. Among the nine lymph nodes identified at histology, two were of a metastatic nature $(5 \mathrm{~mm}$ each), without tumor extension beyond the lymph node capsule. According to the pTNM system, the disease was classified as T2b, N1a and Mx (2).

The patient was discharged from the hospital on day 3 , and radioiodine ablation was scheduled for 5 weeks later. Information about the radioiodine therapy was discussed and the patient was given a booklet reiterating that information to take home. She was advised 


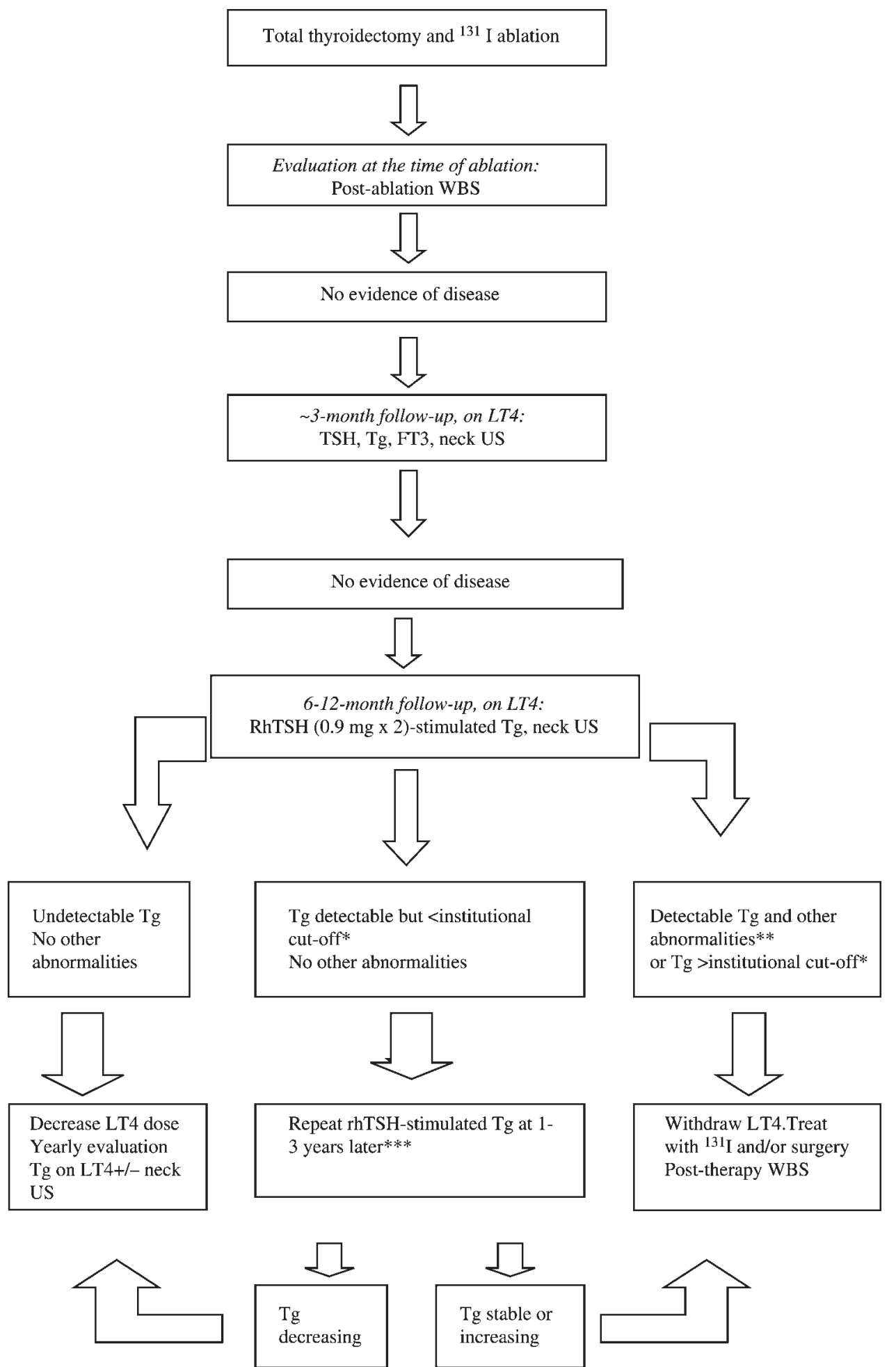

Figure 1 Recommended protocol for follow-up of differentiated thyroid carcinoma in low-risk patients after adjuvant radioiodine treatment (1). Low-risk patients are defined as individuals without distant metastases, extensive neck disease (pT4) or poorly differentiated histotypes who have received adequate surgery and, where indicated, radioiodine ablation, and have no evidence of disease in the evaluation performed in the 6-12 months following initial treatment. Low-risk patients with anti-Tg antibodies should be followed according to other protocols. FT3, free tri-iodothyronine; rhTSH, recombinant human thyroid-stimulating hormone; US, ultrasonography; WBS, whole-body scan; LT4, L-thyroxine; $+/-$, with or without. *The Tg threshold should be determined after rhTSH stimulation for each assay method. **Any suspicious finding on neck US warrants fine-needle aspiration (FNA) with cytological evaluation and measurement of $\mathrm{Tg}$ concentration in the aspirate. ${ }^{* * *}$ This interval depends on exact Tg level and on the clinical context. 
not to take any thyroid hormone therapy, to follow a low iodine diet and to avoid any pharmaceutical iodine contamination. She was also advised to use an efficient contraceptive method and not to become pregnant during the 6 months following the radioiodine treatment.

When the patient returned to the hospital as scheduled she was clinically hypothyroid and had been unable to go back to work since surgery. Indeed, she was extremely anxious, mainly because she had to wait for more than a month before receiving radioiodine ablation which had been described as the second part of the initial treatment. On admission, serum TSH was $64 \mu \mathrm{U} / \mathrm{ml}$ and serum $\mathrm{Tg}$ was $7 \mathrm{ng} / \mathrm{ml}$ with negative anti-Tg autoantibodies and a normal recovery test. A therapeutic activity $(100 \mathrm{mCi} / 3700 \mathrm{MBq})$ of 131-iodine (131-I) was given. She was advised to drink at least 2 liters of liquid per day, to add lemon juice to all water that she drank and to chew gum; a laxative treatment was given throughout hospitalization. On day 3, after she had taken a shower and changed her clothes, a WBS was performed (Fig. 2). It disclosed uptake in thyroid remnants representing $0.2 \%$ of the administered activity; there was no pathological uptake outside the thyroid bed. Indeed, physiological radioiodine accumulation was present in the salivary glands, mouth, stomach, colon and bladder. The whole body retention was about $6 \%$ of the administered activity and this permitted the patient to be discharged from the hospital. She was instructed to avoid close contact with pregnant women and young children for a week.

Before leaving the hospital, the patient was placed on LT4 treatment at a daily dose of $125 \mu \mathrm{g}$ (body weight, $55 \mathrm{~kg}$ ). Three months after the initiation of LT4 treatment, serum TSH, free thyroxine (FT4), FT3 and Tg measurements were performed: serum TSH was $0.1 \mu \mathrm{U} / \mathrm{ml}$, serum FT3 was normal and serum FT4 was at the upper limit of the normal range. Serum Tg was undetectable $(<0.7 \mathrm{ng} / \mathrm{ml}$, i.e. below the functional sensitivity limit, using the Dynotest kit; BRAHMS, Berlin, Germany) with negative anti-Tg antibodies and a normal recovery test.

In a follow-up visit 9 months later (i.e. $\sim 12$ months after initial treatment of DTC), neck ultrasonography disclosed no significant abnormality. The patient received an intramuscular injection of $\operatorname{rhTSH}(0.9 \mathrm{mg})$ on 2 consecutive days and serum Tg was measured 3 days after the second injection. Tg concentration remained undetectable with negative anti-Tg antibodies and a normal recovery test.

In view of the absence of detectable disease, the LT4 daily dose was decreased to $100 \mu \mathrm{g}$ and serum TSH level was measured again 3 months later. At that time, serum TSH was $0.8 \mu \mathrm{U} / \mathrm{ml}$, and the daily dosage of LT4 was maintained unchanged. The patient was followed-up on a yearly basis. Three years later, serum Tg was still undetectable during LT4 treatment,

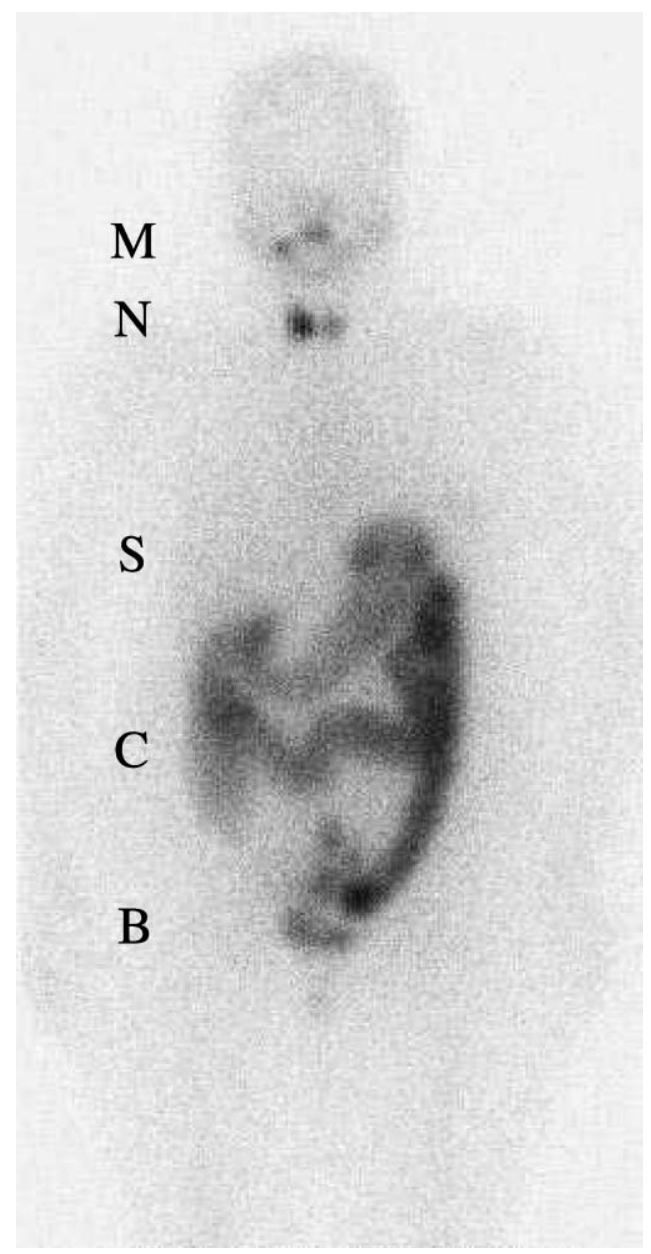

Figure 2 Post-ablation 131-I WBS performed 3 days after the administration of $100 \mathrm{mCi} / 3700 \mathrm{MBq}$. Uptake in thyroid remnant $(\mathrm{N})$ is low $(0.2 \%$ of the administered activity) and no significant pathological focus of uptake was found outside the thyroid bed. Note the physiological accumulation of radioiodine in the salivary glands and mouth (M), stomach (S), colon (C) and bladder (B).

but neck ultrasonography disclosed a suspicious $6 \mathrm{~mm}$ lymph node. A fine-needle aspiration cytology (FNAC) performed under echographic guidance showed inflammatory cells; the $\mathrm{Tg}$ level in the fluid aspirate was undetectable. The lymph node was considered reactive and the patient was reassured. These negative findings were confirmed by a control ultrasonography performed 3 months later; this did not disclose any significant abnormality.

During the next annual follow-up visit the patient expressed concern about the potential consequences on pregnancy outcome of her radioiodine ablation 5 years earlier. The answer was that there was no contraindication for a pregnancy, and the patient soon became pregnant. During pregnancy, the LT4 daily dose was increased to $150 \mu \mathrm{g}$ in the second month and the serum TSH level was maintained within the normal range, as shown by TSH measurements performed every 2 months. Nine months after conception, 
a healthy boy was born and the patient resumed her previous LT4 regimen of $100 \mu \mathrm{g}$ daily. An rhTSHstimulated serum Tg determination and neck ultrasonography were scheduled a year later, i.e. $\sim 5$ years after the first control. Serum Tg remained undetectable, and neck ultrasonography did not disclose any abnormality.

\section{Comments}

(A) The thyroid nodule was asymptomatic and found incidentally by the patient herself, and at the present time such is the case for most thyroid nodules (3). There were no suspicious findings at the initial clinical examination, but this does not exclude a malignancy. Indeed, an FNAC is warranted for any thyroid nodule $>1 \mathrm{~cm}$ in diameter, and even for any smaller nodule when ultrasonographic findings are suspicious (i.e. solid hypoechoic appearance, with irregular or blurred margins, intranodular vascular pattern and presence of microcalcifications) (4). The finding of characteristic nuclear abnormalities at cytology permits the very accurate diagnosis of papillary thyroid carcinoma, and this diagnosis led to surgery and also indicated the extent of surgical resection. Serum TSH determination is useful to screen for a hot nodule and, when serum TSH is low or undetectable, a thyroid scintigraphy will search for a toxic adenoma. A chronic thyroiditis is suspected when anti-thyroid autoantibodies are present and when ultrasonography discloses a characteristic hypoechoic pattern; even when such abnormalities are present, an FNAC of any thyroid nodule should be performed to differentiate a benign or malignant epithelial tumor from a lymphocytic proliferation. Several researchers recommend the measurement of serum calcitonin at the time of initial assessment of all patients with thyroid nodule, to detect otherwise unsuspected medullary thyroid carcinoma (5), but this is still disputed. Medullary tumor, although rare (fewer than 1 in 250 thyroid nodules) is frequently missed by cytology and may be confused with other thyroid tumors or even with a benign proliferation.

(B) Surgery included a total thyroidectomy because papillary thyroid carcinoma is frequently multifocal and is bilateral in $20-80 \%$ of cases $(6-9)$. A dissection of the central neck compartment (including the ipsiand contralateral paratracheal areas) was also performed because lymph node metastases are found in $35-65 \%$ of cases of papillary thyroid carcinoma. This dissection may be extended to the ipsilateral supraclavicular area through the horizontal incision. A modified neck dissection would be indicated in case of lymph node metastases in the jugulocarotid chain. In any case, en bloc dissection should be preferred to lymph node picking. There was no morbidity, the voice being unchanged postoperatively with a normal vocal cord examination, and calcemia and parathormone level
(PTH 1-84) remained within the normal range. In fact, with the use of modern surgical techniques, and when the procedure is performed by a skilled surgeon, the morbidity rate of total thyroidectomy and of central neck dissection has greatly decreased in recent years. Indeed, the extent of surgical resection and lymph node dissection continues to be controversial, but the above protocol offers the best chance to remove all neoplastic foci with a minimal morbidity.

(C) Radioiodine ablation is usually recommended in patients with a $\mathrm{T} 2$ tumor $(>2 \mathrm{~cm})$, and in all tumors with extension beyond the thyroid capsule or with lymph node metastases, because the risk of persistent or recurrent disease is substantial in these cases. Radioiodine ablation will destroy normal thyroid remnants and neoplastic cells, facilitating follow-up and reducing the risk of recurrence $(6,7)$. No thyroid scan was performed before the ablation because, after total thyroidectomy performed by a skilled surgeon, uptake in thyroid remnants is routinely lower than $2 \%$ (10). A scan in fact would not be beneficial, but instead could induce stunning, that is transiently decreased uptake of subsequent radioiodine treatment related to irradiation of thyroid cells by the diagnostic radioiodine activity $(11,12)$. The presence of only small thyroid remnants with a low uptake was shown by the WBS performed 3 days after the administration of ablative radioiodine, confirming that a total thyroidectomy had been performed. Because the uptake in thyroid remnants was low, the WBS was considered highly informative and permitted the exclusion of functional persistent disease. Iodine uptake in thyroid remnants depends on remnant size, on TSH stimulation and on iodine intake from sources other than radioiodine. This is why iodine contamination should be avoided by instructing patients to follow a low iodine diet for 1-2 weeks and to discontinue pharmaceutical or 'alternative medicine' products such as health or multivitamin pills (13). Moreover, in cases of doubt about iodine contamination or, even better, as routine practice, urinary iodine should be measured and elevations $(>200 \mu \mathrm{g} / \mathrm{l})$ should be excluded before giving any 131-I.

After prolonged withdrawal, serum TSH should be above $25-30 \mu \mathrm{U} / \mathrm{ml}$ at the time of ablative radioiodine administration. If concentrations are not above these levels, thyroid hormone withdrawal should be continued for 1 or 2 more weeks, after which serum TSH should be measured again. Alternatively, soon after surgery, patients may start T3 treatment, which should be withdrawn 2 weeks before ablation; this strategy will decrease the length of the hypothyroid period. Indeed, in the near future, rhTSH might be approved for radioiodine ablation in the clinical indication seen in our patient (pT2 with minimal lymph node disease). Use of rhTSH should allow ablation to be performed during LT4 treatment, a few days or a week or two after surgery, thereby avoiding a month-long period of 
inability to work, anxiety and progressive hypothyroidism (14-16). A standard 131-I activity of $100 \mathrm{mCi} / 3700 \mathrm{MBq}$ was administered, aiming at delivering a radiation dose of about $300 \mathrm{~Gy}$ to thyroid remnants. A lower activity $(30 \mathrm{mCi} / 1100 \mathrm{MBq})$ may be used in patients with small thyroid remnants when there is no suspicion of persistent disease, the rate of successful ablation being similar in such patients when using low (>25 mCi/925 MBq) or higher 131-I activities (17). In cases where rhTSH is used for ablation, a higher activity will probably be warranted because the shorter body retention of radioiodine will decrease its bioavailability (as well as whole body exposure).

(D) The initial LT4 daily dose is around $2 \mu \mathrm{g} / \mathrm{kg}$ body weight in young adults, being higher in children and lower in elderly patients (18). LT4 should be taken in a single dose in the morning, on an empty stomach, 20-30 min before breakfast. The TSH level is controlled at 3 months after initiation, because $6-8$ weeks is the minimal period for this level to reach an equilibrium. The objective of LT4 treatment at that time is to obtain a low but detectable serum TSH level, around $0.1 \mu \mathrm{U} / \mathrm{ml}$ with a normal FT3 concentration that permits the exclusion of any overdosage. Serum Tg is measured in the same blood sample to ascertain the absence of detectable disease, as occurred in the present case.

(E) The search for persistent or recurrent disease is based first on surgical and histological reports: in our patient, surgery was complete and pathology confirmed the diagnosis of papillary thyroid carcinoma. Indeed, the size of the thyroid nodule with several microscopic foci and the presence of central lymph node metastases indicated radioiodine treatment. Because the uptake in thyroid remnants was low, the WBS performed with the ablative activity $(100 \mathrm{mCi} / 3700 \mathrm{MBq})$ could be considered more sensitive than any WBS performed with a lower diagnostic activity $(2-5 \mathrm{mCi} / 74-185 \mathrm{MBq})$, whether the diagnostic WBS was performed before or several months after the ablation (Fig. 3). In fact, recent studies have shown that a WBS with a diagnostic activity performed some months after ablation confirmed total ablation (absence of visible uptake or visible uptake $<0.1 \%$ ) in the large majority of patients. However, diagnostic scan has not revealed any focus of uptake outside the thyroid bed in any patient in whom serum Tg remained undetectable following TSH stimulation (19-28). These are the reasons why no diagnostic WBS was performed at the $\sim 1$-year control. Also, the definition of successful ablation has changed: in low-risk patients in whom the post-ablation WBS has shown low uptake in a thyroid remnant and no uptake outside the thyroid bed, an undetectable serum Tg level following TSH stimulation might be considered to indicate success.

In patients with persistent or recurrent disease, serum $\mathrm{Tg}$ is frequently lower following rhTSH

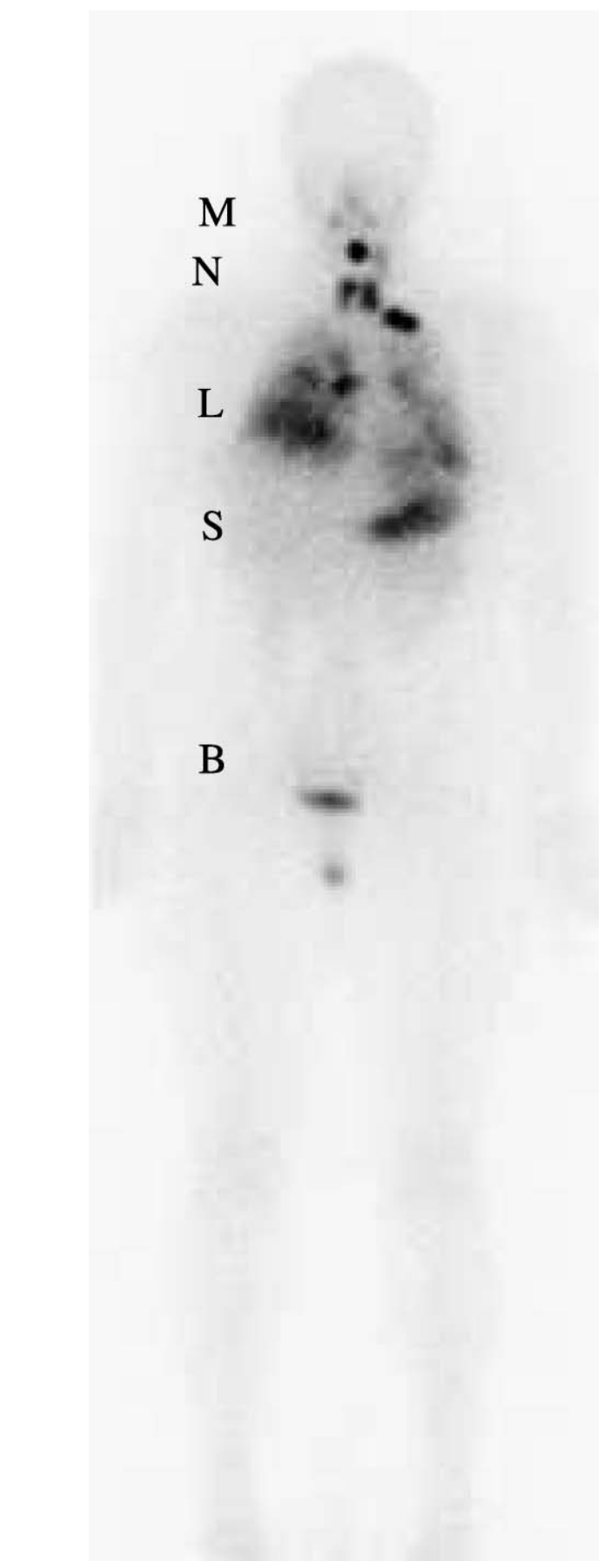

Figure 3 Post-ablation 131-I WBS performed 3 days after the administration of $100 \mathrm{mCi} / 3700 \mathrm{MBq}$. Uptake in thyroid remnant is low and uptake in neck lymph node metastases $(\mathrm{N})$ and in lung metastases (L) is clearly visible. Physiological uptake is visible in the salivary glands and mouth (M), stomach (S) and bladder (B).

injections than following prolonged LT4 withdrawal; this is the rationale for using a sensitive immunoradiometric (IRMA) method, with a functional sensitivity lower than $0.5-1.0 \mathrm{ng} / \mathrm{ml}$, for measuring serum $\mathrm{Tg}$. It is also the rationale for considering any detectable 
stimulated serum Tg value grounds for further investigation (see below). In these conditions, both methods (rhTSH and withdrawal Tg) provide similar sensitivity in disease detection. Therefore, the use of rhTSH rather than withdrawal as an adjunct to $\mathrm{Tg}$ measurement does not imply a need for more frequent testings or more expensive imaging modalities. Rather, rhTSHstimulated serum Tg determination should be considered an equivalently sensitive alternative to $\mathrm{Tg}$ testing after prolonged thyroid hormone withdrawal, to be used in exactly the same way. Where approved, rhTSH is the preferred TSH stimulation method, because it avoids hypothyroidism, thereby improving the quality of life, productivity and satisfaction with medical care of the patients being followed, and safety of and adherence to follow-up.

At present, over $80 \%$ of patients will have undetectable serum Tg following rhTSH stimulation; among them, the rare cases of false negative serum Tg determinations are almost always related to the presence of small lymph node metastases in the neck that can be detected by high-resolution ultrasonography (26-28). Prospective studies have shown that the risk of recurrence in patients with undetectable $\mathrm{Tg}$ after thyroid hormone withdrawal and normal neck ultrasonography is less than $0.5 \%$ during the subsequent 10 years $(10,20)$. Rare discrepant results (negative serum Tgpositive diagnostic WBS) have been observed during long-term follow-up in patients who have already been treated with radioiodine for persistent or recurrent disease (29). Thus, the daily LT4 dose can be reduced with the aim of obtaining a serum TSH level within the normal range and avoiding any side-effects on bone and heart (30). In fact, prospective studies of patients with detectable serum TSH have shown such a low risk of recurrence that the care of a majority of patients can hardly be improved by suppressing TSH secretion; TSH suppression is indicated only in the few patients with persistent disease or high risk of recurrence $(10,20)$.

The 6- to 12-month serum Tg measurement should be performed on LT4 treatment, with the use of rhTSH stimulation to increase the sensitivity of this test. Subsequent annual follow-up is performed on LT4 treatment, with serum TSH and Tg determinations and neck ultrasonography. Whether another stimulated $\mathrm{Tg}$ measurement may be useful in these patients, for instance 3-5 years after the first control, is not established, and indeed requires further study. Also, it is far from clear whether there is any benefit to the extensive use of neck ultrasonography in these patients and the discovery of neck lymph node metastases when these are $<5 \mathrm{~mm}$ in diameter rather than slightly larger. Sonography with FNAC of suspicious nodes gives $95 \%$ true positive results, when analyzed postoperatively $(26-28,31)$. However, criteria of suspicion at ultrasonography are difficult to appreciate in the case of small lymph nodes. Thus, false positive sonography findings are unavoidable and many FNACs will show only inflammatory cells. Also, cytology may be difficult or even falsely negative in lymph node with small metastases or partial involvement, and Tg determination in the aspirate increases the reliability of fineneedle biopsy (32).

\section{Other situations}

\section{Microcarcinoma}

When a single microcarcinoma $(<1 \mathrm{~cm}$ in diameter $)$ is found at histological examination after a partial thyroidectomy performed for a benign nodule or a multinodular goiter, no further treatment (surgery or radioiodine) is indicated. In fact, in these patients, the long-term risk of recurrence in the contralateral lobe is $3 \%(6-8)$. However, a completion thyroidectomy is justified in case of multifocality, because the risk of a contralateral tumor and thus of recurrence is $20 \%$ or even more; in the case of completion thyroidectomy, a central neck dissection is also advised and the risk of recurrence will then be $<5 \%$. Patients thyroidectomized for multifocal microcarcinoma are followed up on LT4 treatment with unstimulated serum Tg determination and neck ultrasonography. Whether these patients require radioiodine ablation remains controversial, with different centers either omitting the procedure, performing it routinely, or performing it only in patients with a large number of neoplastic foci.

\section{pT3-4 tumor}

In cases of tumor extension beyond the thyroid capsule, the risk of persistent or recurrent disease and of cancerrelated death is indeed much higher than in our patient (6-8). The same protocol should be used for surgery, and radioiodine ablation should be carried out with an activity of $100 \mathrm{mCi} / 3700 \mathrm{MBq}$ following thyroid hormone withdrawal. The discovery of persistent disease is much more frequent and may indicate further therapeutic interventions. Also, any detectable serum $\mathrm{Tg}$ level during follow-up should lead to the search for recurrent disease by ultrasonography and 131-I WBS.

\section{Lateral lymph node metastases}

When lateral lymph node involvement is found pre- or intraoperatively, a modified lymph node dissection is indicated on the side of the neck involved.

\section{Incomplete surgery}

In the case of lobectomy, a completion thyroidectomy should be considered for any papillary or follicular carcinoma $(9,33-39)$. The only exception is the case of a single focus of papillary microcarcinoma, as discussed above. 
When ablation is warranted and less than total thyroidectomy has been performed, a diagnostic WBS may be indicated before the administration of the ablative activity of radioiodine to assess the uptake in thyroid remnants and the need for additional surgery before ablation. Total thyroidectomy maximizes qualityadjusted life expectancy in both high-and low-risk patients with papillary thyroid carcinoma $(37,39)$. Therefore, in cases of large thyroid remnants, further surgery may be considered. In experienced hands, completion surgery is safe $(35,36)$ and it frequently results in the detection and excision of additional cancer foci (9).

When ablation is performed in the absence of additional surgery, despite a high thyroid uptake on pre-ablation diagnostic WBS, the post-ablation WBS may be poorly informative, and the ablation success rate reduced. In this situation, a control diagnostic WBS may be performed 6-12 months later to search for uptake outside the thyroid bed that may have not been visualized on the post-ablation WBS, and for persistent uptake in the thyroid bed (Fig. 4).

\section{Uptake outside the thyroid bed}

The discovery on the post-ablation WBS of foci of uptake outside the thyroid bed indicates persistent disease, which requires further treatment. Foci of uptake outside the thyroid bed are more frequently observed in pT3-4 or N1 tumors. The detection of persistent disease at that time and its treatment will indeed reduce the risk of subsequent recurrence $(6-8,39)$.

\section{Anti-Tg antibodies}

At the beginning of follow-up, both a serum anti-Tg antibody determination and a $\mathrm{Tg}$ recovery test are advised. Anti-Tg autoantibodies are detected initially by direct measurement in $15-25 \%$ of patients with thyroid carcinoma $(40,41)$. The recovery test, which consists of adding a known amount of $\mathrm{Tg}$ to the serum sample and then measuring the serum Tg (recovery) in the sample, discloses interferences in only $1-2 \%$ of thyroid cancer patients (6). When IRMA methodology is used for measuring Tg, interferences lead only to underestimation of Tg levels. There is, however, no relationship between the antibody titer and the presence of interference. In addition, the recovery test may miss interferences in some sera, and caution is advised when anti-Tg antibodies are found and the recovery test is normal. For these reasons, serum $\mathrm{Tg}$ cannot be used as a reliable marker of disease in the presence of Tg antibody or of interference $(40,41)$. Follow-up should rely on neck ultrasonography and, depending on risk factors, also on 131-I WBS.

When antibodies are present in the initial measurement, they should be screened at each subsequent control until they become undetectable. In the absence of

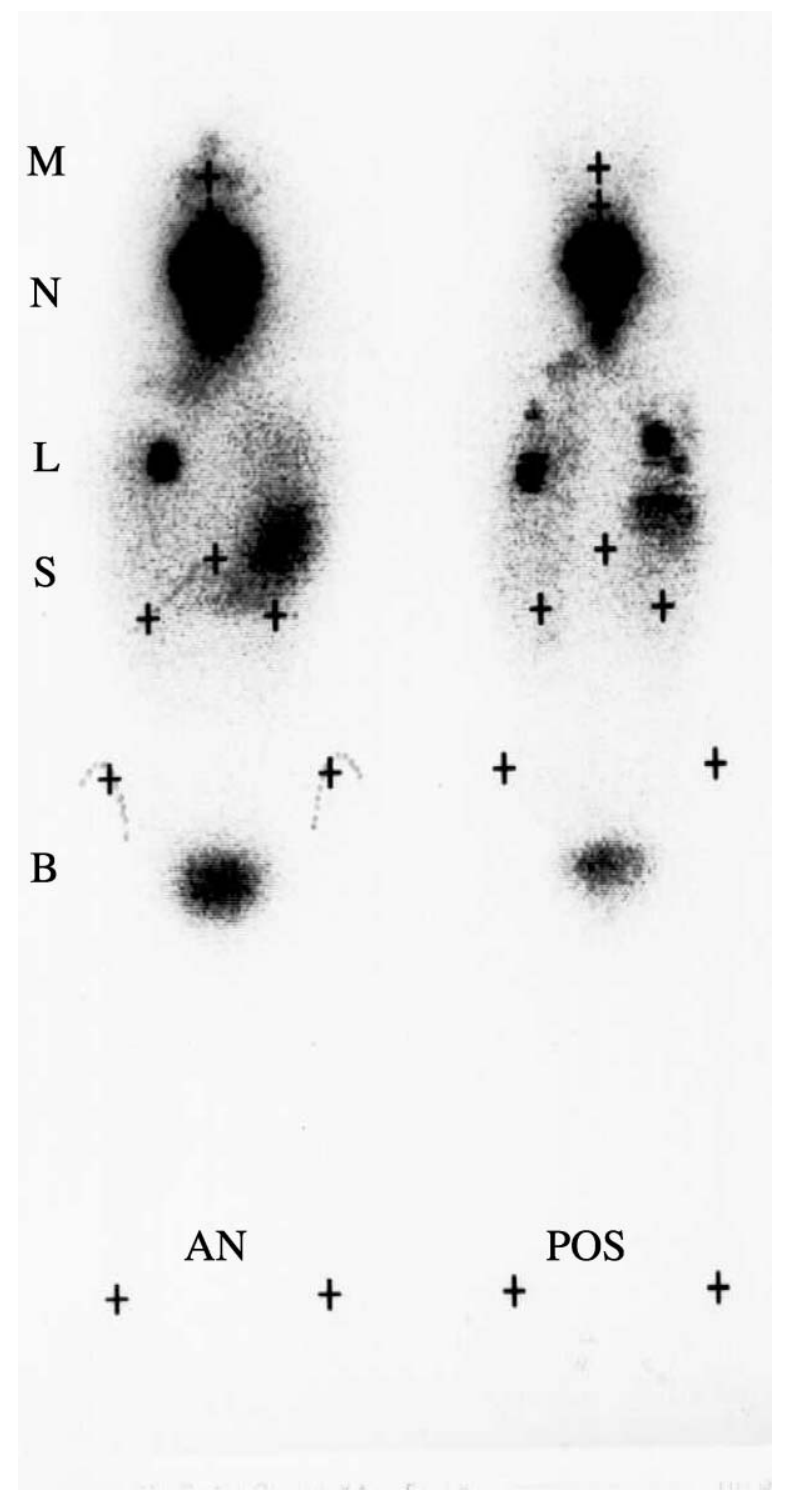

Figure 4 Post-ablation 131-I WBS performed 3 days after the administration of $100 \mathrm{mCi} / 3700 \mathrm{MBq}$. Uptake in the thyroid remnant is high (4\% of the administered activity), and the sensitivity of WBS for detecting lymph node metastases in the neck is low. Uptake in lung metastases is clearly visible. M, mouth; N, neck; L, lungs; $\mathrm{S}$, stomach; B, bladder. AN, anterior view; POS, posterior view; crosses indicate anatomical marks.

disease, anti-Tg antibodies will disappear within the first 2 years of follow-up (40-42), and persistence of such antibodies should lead to a search for neoplastic foci.

\section{Detectable serum Tg level}

A detectable serum $\mathrm{Tg}$ level should be interpreted according to three parameters: (a) the level itself, (b) the condition under which serum Tg was obtained (unstimulated during LT4 treatment, stimulated following thyroid hormone withdrawal, or stimulated following rhTSH administration) and (c) the time 
after treatment at which serum Tg was measured. In modern $\mathrm{Tg}$ assays, the functional sensitivity is 0.5$1.0 \mathrm{ng} / \mathrm{ml}$, and any value above this limit should be considered detectable. A basic principle is that there is no detectable $\mathrm{Tg}$ level below which the risk of persistent or recurrent disease can be totally excluded. However, the risk increases with higher serum $\mathrm{Tg}$ levels, and this observation led to the definition of institutional cut-off levels above which the probability of detecting neoplastic foci by various methods, i.e. ultrasonography, 131-I WBS, computed tomography (CT) scan, becomes substantial. At present, the use of very sensitive methods for serum Tg determination (with functional sensitivity as low as 0.1 or even $0.01 \mathrm{ng} / \mathrm{ml}$ ) will dramatically increase the number of patients with detectable serum $\mathrm{Tg}$ and no other evidence of disease, and thus may decrease the costeffectiveness of follow-up of DTC patients.

Serum Tg will increase by a factor of 5 to 10 following prolonged thyroid hormone withdrawal, or by a smaller factor following rhTSH stimulation. Use of TSH stimulation will thus reduce the risk of false negative serum Tg determinations (which are often due to small lymph node metastases in the neck that can be detected by ultrasonography). However, use of TSH stimulation also increases the number of patients with detectable, albeit low, serum Tg levels (below the institutional cut-off) who have no other evidence of disease. In individuals with normal serum TSH levels, serum $\mathrm{Tg}$ will increase by $0.5-1.0 \mathrm{ng} / \mathrm{ml}$ per additional gram of healthy thyroid tissue. Following TSH stimulation, there is also a general relationship between the level of $\mathrm{Tg}$ and the mass of malignant thyroid tissue $(41,43)$. However, it must be remembered that the capacity of $\mathrm{Tg}$ production depends also on the degree of differentiation of the neoplastic cells and, as noted above, the degree of TSH stimulation.
When measured following TSH stimulation some months after initial treatment, serum Tg is detectable in $5-20 \%$ of patients with no other evidence of disease. The positive predictive value of this finding is low at that time, but will improve if $\mathrm{Tg}$ remains detectable during the subsequent follow-up. In fact, serum Tg following TSH stimulation will normalize in the absence of any further treatment in two out of three of these patients, in whom the risk of subsequent recurrence will be very low $(44,45)$. In the other third, serum $\mathrm{Tg}$ will remain stable or increase, and the risk of recurrence will be high; any method to localize persistent or recurrent disease is then warranted, including a WBS with a high 131-I activity, a neck and chest CT scan and eventually a fluorodeoxyglucose positron emission tomography scan $(46,47)$. Thus, when serum $\mathrm{Tg}$ is detectable following TSH stimulation at the control performed during the year after initial treatment, it is recommended to again measure serum Tg 1-2 years later, following TSH stimulation.

\section{Conclusion}

Our clinical case illustrates the application in routine practice of our algorithm for follow-up of low-risk DTC. The definition 'low risk' is no longer based on initial staging but rather now refers to patients treated by adequate surgery and, when indicated, by adjuvant radioiodine treatment, who have no evidence of disease in evaluation performed in the 6-12 months following initial treatment. In particular, we want to stress the value of stimulated serum $\mathrm{Tg}$ determination as the most sensitive test in this population, now that rhTSH is fully available for TSH stimulation, and of the combination of serum $\mathrm{Tg}$ measurement with the routine use of neck ultrasonography (Fig. 5). In contrast, in

\section{SENSITIVITY FOR DETECTION OF NECK RECURRENCES}

\begin{tabular}{cccc}
$\begin{array}{c}\text { STUDY INFORMATION: } \\
\text { Reference }\end{array}$ & 26 & 27 & \\
$\mathrm{~N}_{1} / \mathrm{Pts}$ & $27 / 340$ & $51 / 494$ & $38 / 456$ \\
\hline METHOD: & & & \\
Tg/TSH & $85 \%(\mathrm{rhTSH})$ & $57 \%(\mathrm{wd})$ & $82 \%(\mathrm{wd})$ \\
131 I WBS & $21 \%$ & $45 \%$ & $34 \%$ \\
Neck US & $70 \%$ & $94 \%$ & $100 \%$ \\
Neck US+Tg/TSH & $96 \%$ & $99.5 \%$ & $100 \%$
\end{tabular}

Figure 5 Sensitivity of various methods used for detecting neck recurrences. $\mathrm{N}_{1}$, patients with lymph node metastases; Pts, patients; $\mathrm{Tg} / \mathrm{TSH}, \mathrm{Tg}$ level measured following TSH stimulation obtained either during LT4 treatment with rhTSH or after withdrawal of thyroid hormone treatment (wd); US, ultrasonography. 
low-risk patients without anti-Tg antibodies, diagnostic WBS should be performed only with the aim of localizing persistent or recurrent disease in individuals with elevated serum $\mathrm{Tg}$ levels. In addition, we want to emphasize that rhTSH-stimulated serum Tg determination using a modern IRMA should be considered an equivalently sensitive alternative to serum Tg testing following prolonged thyroid hormone withdrawal, to be used in exactly the same way. Where approved, rhTSH is the preferred stimulation method because it avoids hypothyroidism and its unpleasant and sometimes deleterious consequences. The protocol described in this and our previous paper in this Journal will simplify and improve the cost-effectiveness of the routine follow-up of low-risk patients, and will enhance their quality of life.

\section{References}

1 Schlumberger M, Berg G, Cohen O, Duntas L, Jamar F, Jarzab B, Limbert E, Lind P, Pacini F, Reiners C, Sànchez Franco F, Toft A \& Wiersinga WM. Follow-up of low-risk patients with differentiated thyroid carcinoma: a European perspective. European Journal of Endocrinology 200450 105-112.

2 American Joint Committee on Cancer. Chapter 8: Thyroid. In AJCC Cancer Staging Handbook, edn 6, chapter 8, pp 89-98. New York: Springer, 2002.

3 Hegedus L, Bonnema SJ \& Bennedbaek FN. Management of simple nodular goiter. Endocrine Reviews 200324 102-132.

4 Papini E, Guglielmi R, Bianchini A, Crescendi A, Taccogna S, Nardi F, Panunzi C, Rinaldi R, Toscano V \& Pacella CM. Risk of malignancy in nonpalpable thyroid nodules: predictive value of ultrasound and color-doppler features. Journal of Clinical Endocrinology and Metabolism 200287 1941-1946.

5 Elisei R, Bottici V, Luchetti F, Di Coscio G, Romei C, Grasso L, Miccoli P, Iacconi P, Basolo F, Pinchera A \& Pacini F. Impact of routine measurement of serum calcitonin on the diagnosis and outcome of medullary thyroid cancer: experience in 10,864 patients with nodular thyroid disorders. Journal of Clinical Endocrinology and Metabolism 200489 163-168.

6 Schlumberger MJ. Medical progress: papillary and follicular thyroid carcinoma. New England Journal of Medicine 1998338 297-306.

7 Sherman SI. Thyroid carcinoma. Lancet $2003361501-511$.

8 Schlumberger MJ, Pacini F. Thyroid Tumors, edn 2, Paris: Editions Nucleon, 2003.

9 Pacini F, Elisei R, Capezzone M, Miccoli P, Molinaro E, Basolo F, Agate L, Bottici V, Raffaelli M \& Pinchera A. Contralateral papillary thyroid cancer is frequent at completion thyroidectomy with no difference in low-and high risk patients. Thyroid 200111 877-881.

10 Cailleux AF, Baudin E, Travagli JP, Ricard M \& Schlumberger M. Is diagnostic iodine-131 scanning useful after total thyroid ablation for differentiated thyroid cancer? Journal of Clinical Endocrinology and Metabolism $2000 \mathbf{8 5} 175-178$.

11 Lees W, Mansberg R, Roberts J, Towson J, Chua E \& Turtle J. The clinical effects of thyroid stunning after diagnostic whole-body scanning with $185 \mathrm{MBq}$ 131I. European Journal of Nuclear Medicine and Molecular Imaging 200229 1421-1427.

12 Park HM, Perkins OW, Edmondson JW, Schnute RB \& Manatunga A. Influence of diagnostic radioiodines on the uptake of ablative dose of iodine-131. Thyroid 1994 4 49-54.

13 Pluijmen MJ, Eustatia-Rutten C, Goslings BM, Stokkel MP, Arias AM, Diamant M, Romijn JA \& Smit JW. Effects of lowiodine diet on postsurgical radioiodide ablation therapy in patients with differentiated thyroid carcinoma. Clinical Endocrinology $20037428-435$.
14 Berg G, Lindstedt G, Suurküla M \& Jansson S. Radioiodine ablation and therapy in differentiated thyroid cancer under stimulation with recombinant human thyroid-stimulating hormone (rhTSH). Journal of Endocrinological Investigation 200225 44-52.

15 Robbins RJ, Larson SM, Sinha N, Shaha A, Divgi C, Pentlow KS, Ghossein R \& Tuttle RM. A retrospective review of the effectiveness of recombinant human TSH as a preparation for radioiodine thyroid remnant ablation. Journal of Nuclear Medicine 200243 $1482-1488$

16 Dow KH, Ferrell BR \& Anello C. Quality-of-life changes in patients with thyroid cancer after withdrawal of thyroid hormone therapy. Thyroid 19977 613-619.

17 Bal CS, Kumar A \& Pant GS. Radioiodine dose for remnant ablation in differentiated thyroid carcinoma: a randomized clinical trial in 509 patients. Journal of Clinical Endocrinology and Metabolism 200489 1666-1673.

18 Bartalena L, Martino E, Pacchiarotti A, Grasso L, AghiniLombardi F, Buratti L, Bambini G, Breccia M \& Pinchera A. Factors affecting suppression of endogenous thyrotropin secretion by thyroxine treatment: retrospective analysis in athyreotic and goitrous patients. Journal of Clinical Endocrinology and Metabolism $198764849-855$.

19 Pacini F, Molinaro E, Lippi F, Castagna MG, Agate L, Ceccarelli C, Taddei D, Elisei R, Capezzone M \& Pinchera A. Prediction of disease status by recombinant human TSH stimulated serum Tg in the postsurgical follow-up of differentiated thyroid carcinoma. Journal of Clinical Endocrinology and Metabolism $2001 \mathbf{8 6}$ 5686-5690.

20 Pacini F, Capezzone M, Elisei R, Ceccarelli C, Taddei D \& Pinchera A. Diagnostic 131-iodine whole-body scan may be avoided in thyroid cancer patients who have undetectable stimulated serum $\mathrm{Tg}$ levels after initial treatment. Journal of Clinical Endocrinology and Metabolism 200287 1499-1501.

21 Torlontano M, Crocetti U, D’Aloiso L, Bonfitto N, Di Giorgio A, Modoni S, Valle G, Frasciante V, Bisceglia M, Filetti S, Schlumberger M \& Trischitta V. Serum thyroglobulin and ${ }^{131} \mathrm{I}$ whole body scan after recombinant human TSH stimulation in the follow-up of low-risk patients with differentiated thyroid cancer. The role for neck ultrasonography. European Journal of Endocrinology $2003 \mathbf{1 4 8} 18-24$.

22 Haugen BR, Pacini F, Reiners C, Schlumberger M, Ladenson PW, Sherman SI, Cooper DS, Graham KE, Braverman LE, Skarulis MC, Davies TF, DeGroot LJ, Mazzaferri EL, Daniels GS, Ross DS, Luster M, Samuels MH, Becker DV, Maxon HR, Cavalieri RR, Spencer CA, McEllin K, Weintraub BD \& Ridgeway EC. A comparison of recombinant human thyrotropin and thyroid hormone withdrawal for the detection of thyroid remnant or cancer. Journal of Clinical Endocrinology and Metabolism 199984 3877-3885.

23 Haugen BR, Ridgway EC, McLaughlin B \& McDermott MT. Clinical comparison of whole-body radioiodine scan and serum thyroglobulin after stimulation with recombinant human TSH. Thyroid $20021237-43$.

24 Mazzaferri EL \& Kloos RT. Is diagnostic iodine-131 scanning with recombinant human TSH useful in the follow-up of differentiated thyroid cancer after thyroid ablation? Journal of Clinical Endocrinology and Metabolism 200287 1490-1498.

25 Mazzaferri EL, Robbins RJ, Spencer CA, Braverman LE, Pacini F, Wartofsky L, Haugen BR, Sherman SI, Cooper DS, Braunstein GD, Lee S, Davies TF, Arafah BM, Ladenson PW \& Pinchera A. A consensus report of the role of serum thyroglobulin as a monitoring method for low-risk patients with papillary thyroid carcinoma. Journal of Clinical Endocrinology and Metabolism $2003 \mathbf{8 8}$ 1433-1441.

26 Pacini F, Molinaro E, Castagna MG, Agate L, Elisei R, Ceccarelli C, Lippi F, Taddei D, Grasso L \& Pinchera A. rhTSH-stimulated serum thyroglobulin combined with neck ultrasonography has the highest sensitivity in monitoring differentiated thyroid carcinoma. Journal of Clinical Endocrinology and Metabolism $2003 \mathbf{8 8}$ 3668-3673. 
27 Torlontano M, Attard M, Crocetti U, Tumino S, Bruno R, Costante G, D'Azzo G, Meringolo D, Ferretti E, Sacco R, Arturi F \& Filetti S. Follow-up of low risk patients with papillary thyroid cancer: role of neck ultrasonography in detecting lymph node metastases. Journal of Clinical Endocrinology and Metabolism $2004893402-3407$.

28 Frasoldati A, Presenti M, Gallo M, Caroggio A, Salvo D \& Valcavi R. Diagnosis of neck recurrences in patients with differentiated thyroid carcinoma. Cancer 2003 97 90-96.

29 Robbins RJ, Chon JT, Fleisher M, Larson SM \& Tuttle RM. Is the serum thyroglobulin response to recombinant human thyrotropin sufficient, by itself, to monitor for residual thyroid carcinoma? Journal of Clinical Endocrinology and Metabolism $2002 \mathbf{8 7}$ $3242-3247$

30 Biondi B, Palmieri EA, Lombardi G \& Fazio S. Effects of subclinical thyroid dysfunction on the heart. Annals of Internal Medicine 2002 137 909-914.

31 Frilling A, Görges R, Tecklenborg K, Gaßmann P, Bockhorn M, Clausen M \& Broelsch CE. Value of preoperative diagnostic modalities in patients with recurrent thyroid carcinoma. Surgery 2000128 1067-1074.

32 Pacini F, Fugazzola L, Lippi F, Ceccarelli C, Centoni R, Miccoli P, Elisei R \& Pinchera A. Detection of thyroglobulin in fine needle aspirates of nonthyroidal neck masses: a clue to the diagnosis of metastatic differentiated thyroid cancer. Journal of Clinical Endocrinology and Metabolism $1992 \mathbf{7 4} 1401-1404$.

33 Sanders LE \& Cady B. Differentiated thyroid cancer: reexamination of risk groups and outcome of treatment. Archives of Surgery $1998133419-425$.

34 Kebebew E, Duh QY \& Clark OH. Total thyroidectomy or thyroid lobectomy in patients with low-risk differentiated thyroid cancer: surgical decision analysis of a controversy using a mathematical model. World Journal of Surgery 200024 1295-1302.

35 Pezzullo L, Delrio P, Losito NS, Caraco C \& Mozzillo N. Post-operative complications after completion thyroidectomy for differentiated thyroid cancer. European Journal of Surgical Oncology 1997 23 215-218.

36 Scheumann GF, Seeliger H, Musholt TJ, Gimm O, Wegener G, Dralle H, Hundeshagen H \& Pichlmayr R. Completion thyroidectomy in 131 patients with differentiated thyroid carcinoma. European Journal of Surgery 1996162 677-684.

37 Clark OH, Levin K, Zeng QH, Greenspan FS \& Siperstein A. Thyroid cancer: the case for total thyroidectomy. European Journal of Cancer and Clinical Oncology 198824 305-313.

38 Esnaola NF, Cantor SB, Sherman SI, Lee JE \& Evans DB. Optimal treatment strategy in patients with papillary thyroid cancer: a decision analysis. Surgery $2001130921-930$.
39 Mazzaferri EL. An overview of the management of papillary and follicular thyroid carcinoma. Thyroid 19999 421-427.

40 Spencer CA, Takeuchi M, Kazarosyan M, Wang CC, Guttler RB, Singer PA, Fatemi S, LoPresti JS \& Nicoloff JT. Serum thyroglobulin antibodies: prevalence, influence on serum thyroglobulin measurements, and prognostic significance in patients with differentiated thyroid carcinoma. Journal of Clinical Endocrinology and Metabolism 199883 1121-1127.

41 Demers LM \& Spencer CA. Laboratory support for the diagnosis and monitoring of thyroid disease http://www.nacb.org/lmpg/ thyroid/LMPHstm (7-13-2002).

42 Chiovato L, Latrofa F, Braverman LE, Pacini F, Capezzone M, Masserini L, Grasso L \& Pinchera A. Disappearance of humoral thyroid autoimmunity after complete removal of thyroid antigens. Annals of Internal Medicine 2003139 346-351.

43 Bachelot A, Cailleux AF, Klain M, Baudin E, Ricard M, Bellon N, Caillon B, Travagli JP \& Schlumberger M. Relationship between tumor burden and serum thyroglobulin level in patients with papillary and follicular thyroid carcinoma. Thyroid $2002 \mathbf{1 2}$ $707-771$

44 Baudin E, Do Cao C, Cailleux AF, Leboulleux S, Travagli JP \& Schlumberger M. Positive predictive value of serum thyroglobulin levels, measured during the first year of follow-up after thyroid hormone withdrawal in thyroid cancer patients. Journal of Clinical Endocrinology and Metabolism 200388 1107-1111.

45 Pacini F, Agate L, Elisei R, Ceccarelli C, Lippi F, Molinaro E \& Pinchera A. Outcome of differentiated thyroid cancer with detectable serum $\mathrm{Tg}$ and negative diagnostic ${ }^{131} \mathrm{I}$ whole body scan: comparison of patients treated with high ${ }^{131}$ I activities versus untreated patients. Journal of Clinical Endocrinology and Metabolism $2001864092-4097$.

46 Petrich T, Börner AR, Otto D, Hofmann M \& Knapp WH. Influence of rhTSH on [18F]fluorodeoxyglucose uptake by differentiated thyroid carcinoma. European Journal of Nuclear Medicine and Molecular Imaging $200229641-647$.

47 Chin BB, Patel P, Cohade C, Ewertz M, Wahl R \& Ladenson P. Recombinant human thyrotropin stimulation of fluoro-D-glucose positron emission tomography uptake in well-differentiated thyroid carcinoma. Journal of Clinical Endocrinology and Metabolism 200489 91-95.

Received 12 July 2004

Accepted 22 July 2004 